\title{
Effect of Labor Participation on Transition of Marital State: Application of Markov Chain
}

\author{
Samsik Lee and Hyojin Choi \\ Korea Institute for Health and Social Affairs \\ \{SamsikLee\}lss@kihasa.re.kr
}

\begin{abstract}
This study aims to measure the transition probabilities between marital states by employment status, using the transition matrix of a Markov chain. The data are derived from the Resident Registration System, Population Census, and Vital Registration System. It is found that for not only men but also women, the employment plays an important role to expedite the transition from the single state, the widowed state, or the divorced state to the married state, specifically in childbearing ages. The employment also plays a role to prevent the divorce. It can be strongly suggested from such results that job opportunities and job security should be strengthened to foster the early marriage and thereby the pronatality.
\end{abstract}

Keywords: marital state, labor participation, transition probability

\section{Introduction}

It has been recently known very well that South Korea is one of a few countries, characteristic of lowest low fertility. Indeed, South Korea has experienced a dramatic fertility decline. The total fertility rate dropped from 6.0 in 1960 to the population replacement level of 2.1 in 1983 and thereafter continued to decline even to 1.08 in 2005 . Specifically, the total fertility rate has fluctuated below 1.2 since 2001.

According to the population projection by the Statistics Korea (2011), the working age population will start to decline from 2017, expediting the population aging with great speed. Such a rapid demographic transition will cause labor shortages, lowering of labor productivity, dwindling of domestic consumption, low economic growth, etc. Thus, the Korean government has launched the Basic Plan on Low Fertility and Population Aging to raise the fertility rate since 2006. Despite of the government's efforts, the lowest low fertility phenomenon continues in South Korea.

In South Korea, giving births within legitimate marriage has been considered normal, affected by traditionally long-rooted Confucianism; about 2 percent of births took place outside of legitimate marriage in 2014. Therefore, the change in marriage behaviors has been of great importance in determining the fertility level. In this sense, the postponement of first marriage, persisting among the Korean young people, becomes the center of attention; the mean age at first marriage continues to increase and thereby the proportion of married population to the total, specifically in childbearing ages, has declined rapidly. Family dissolution such as divorce and separation has become a rather general phenomenon in South Korea. It is worthwhile to note that such characteristics of marriage behaviors have accounted for the continuation of lowest low fertility (Lee, et al., 2014).

The change in marriage behaviors is known to be affected by a variety of socioeconomic factors such as education, employment, income level, and values. This study makes an attempt to measure the effect of employment on marriage behaviors; 
the sex and age specific transition probabilities between marital states are calculated by employment status using mathematic and demographic methods. The result is expected to provide a basis on the extent to which the employment related policies is needed to foster the marriages and thereby pro-natality.

\section{Literature Review}

The relationship between employment and marriage has been studied by some researchers. Kim (2006) carried out a logit regression analysis on effect of employment on marriage using the result of 2005 National Survey on Dynamics of Marriage and Fertility; as a result, the unmarried males having a job showed more intentions for marriage than those having not a job, although the relationship between employment and marriage intents seems to be not statistically significant for the unmarried females. Lee (2005)'s study also argued by the results of a probit analysis on the Korean Labor \& Income Panel Study data that the employment status has a positive effect on the probability of choosing marriage for the males but does not show statistical significance for the females.

However, Yoo and Hyun (2010) found from the study applying binominal regression analysis to the Population Census data of 1995, 2000 and 2005 (2\% sample) that those having a job show higher probabilities of marrying than those having not a job for males but those having a job show lower probabilities of marrying than those having not a job for females. Yoon (2012) also show a similar result, by practicing the Survival Analysis on the data of the Korean Labor \& Income Panel Study that being employed increases the marriage transition hazard for males but decreases the marriage transition hazard for females.

Ahn (2010) made a linear probability model on the never-married people using the data from the Survey on Economically Active Population for 2000 and 2008; as a result, the probabilities of being never-married tend to be higher for those people who are not-employed, irregularly-employed or part time-employed. An attempt of regression analysis on Korean Labor \& Income Panel Study also showed that being employed facilitates to enter the marriage compared to being not employed (Ahn, 2010). A multi-regression analysis on the 2009 National Survey on Dynamics of Marriage and Fertility by Lim and Kim (2013) shows that the desired age for marriage is younger for those being employed than those being not-employed.

Thus, many studies agree that having a job may increase the probability of marrying for males. However, no consensus is on the relationship between employment and marriage for females; on the one hand, having a job may play a positive role in that it is considered as one of important conditions for marrying and on the other hand, having a job may play a negative role for marrying in that it can increase the opportunity cost for marrying due to difficulties in work and life balance. It is a worthwhile to analyze the effect of employment on marriage behaviors by age since the probability of family formation or dissolution is an interactive function between employment and age.

\section{Methods and Data}

The marital status could be classified into four states such as single (never married), married, divorced, widowed. The model for transition between marital states can be set up, as shown in Figure 1. In the model, everyone, irrespective of their employment status, will start from the single state. Some of the single people who participate in the labor force will move to the married state. Some of the married people with jobs may move to either the divorced state or the widowed state. Some of either the divorced people or the widowed people who currently participate in the labor force may move to the (re)married state. Of course, some of those remarried people in the labor force may again move to 
either the divorce state or the widowed state. Such transition paths may occur repeatedly. It needs to note that the transition from the married state to the widowed state is not taken into considerations in this study, because this study attempts to measure the effect of employment on marriage. The people with jobs are subject to mortality in the course of transiting between marital states. This transition model is also applied the same for the people with no jobs.

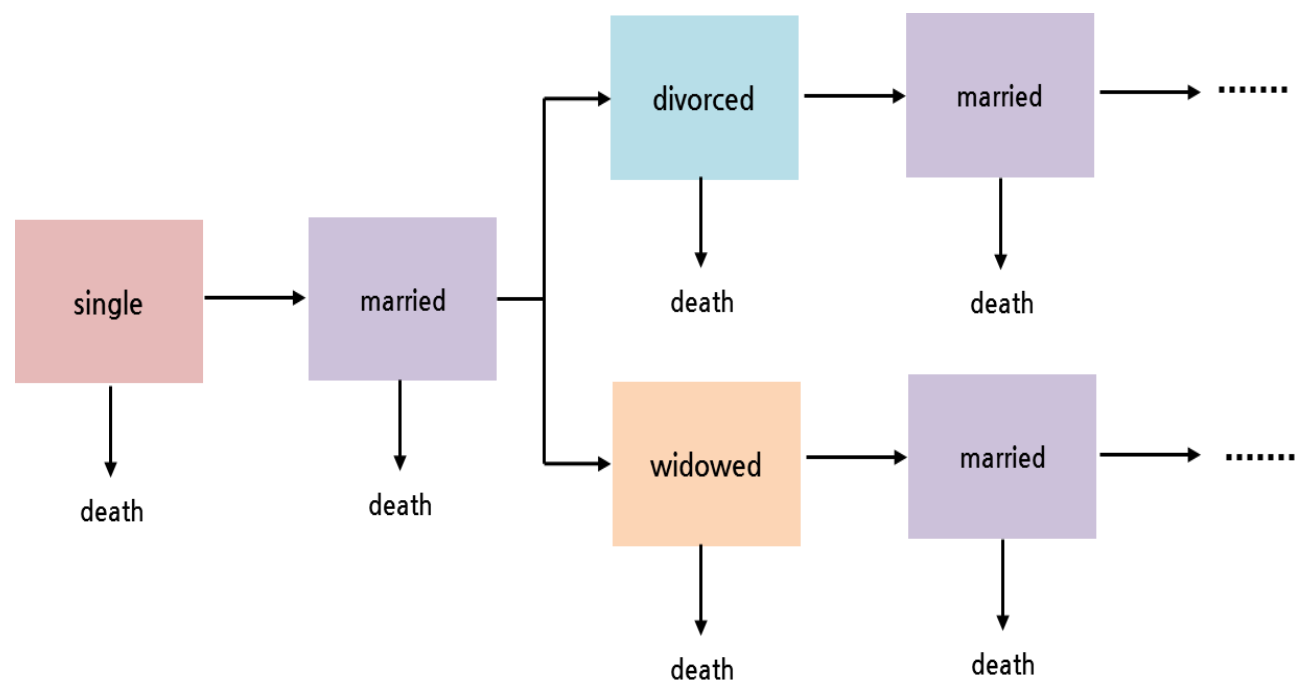

Figure 1. Model for Transition Between Marital States

Based on this model, the sex and age specific transition probabilities between marital states are calculated by the employment status, using a Markov chain. Markov chain transition probability matrix is as follows;



Markov process, an application of multi-state life tables, assumes that transition probabilities depend only on age and current state, independently of the previous state (Siegel, and Swanson, 2004). The transition probabilities are converted by the Greville formula for adjusting some irregularities (refer to Greville, 1981 for the details of Greville formula).

The data for calculating the transition probabilities are derived from Residential Registration System, Population Census, and Vital Registration System, as of 2010. The data from the Residential Registration System is to obtain the population by sex and age. The data from the Population Census is to obtain the population by sex, age, marital state and employment status. The data from the Vital Registration System is to obtain the number of deaths by sex, age and employment status.

In this study, the employment status is classified into two categories such as 'with jobs' and 'without jobs'. The people with jobs include the employed and the people 
without jobs include the unemployed as well as the economically inactive population.

\section{Main Findings}

The people with jobs show higher probabilities to transit from the single state to the married state than the people without jobs (Figure 2). The transition probabilities for the people with jobs reach a peak in their mid-20s and then decline rapidly. The transition probabilities for the people without jobs also reach a peak at a very low level in their mid-20s and then decline rather slowly compared with those with jobs. As a result, there are big gaps in transition probabilities for the mid20 s and the early-30s between two groups of people but the gaps rapidly decrease with age. This pattern appears to be similar for both men and women. However, the transition probabilities are higher for women than men before and after reaching a peak for both people with jobs and without jobs; women tend to marry earlier, almost by three years, than men at younger ages but after the mid-20s the women tend to postpone their marriage more than the men, regardless of employment status. Such a transition pattern implies that participating in the labor force plays a crucial role in expediting transition from the single state to the married state at younger ages but such an employment effect tends to decrease with age (age effect).



Figure 2. Transition Probabilities From the Single State to the Married State

The transition probabilities from the married state to the divorced state appear to be higher for the people without jobs than for the people with jobs (Figure 3); such an employment effect is much more apparent for men than for women, indicating that the men with no job are likely to confront with difficulties in maintaining the marriage life. For all groups of population by sex and employment status, the transition probabilities from the married state to the divorced state decrease due to the age effect, although there are some irregularities at very young ages. The exception is that the transition probabilities for the people without jobs soar in their 40 s for both men and women; it can be pointed out that the people without jobs tend to quit his or her job at middle age and thereby are more likely to divorce. 


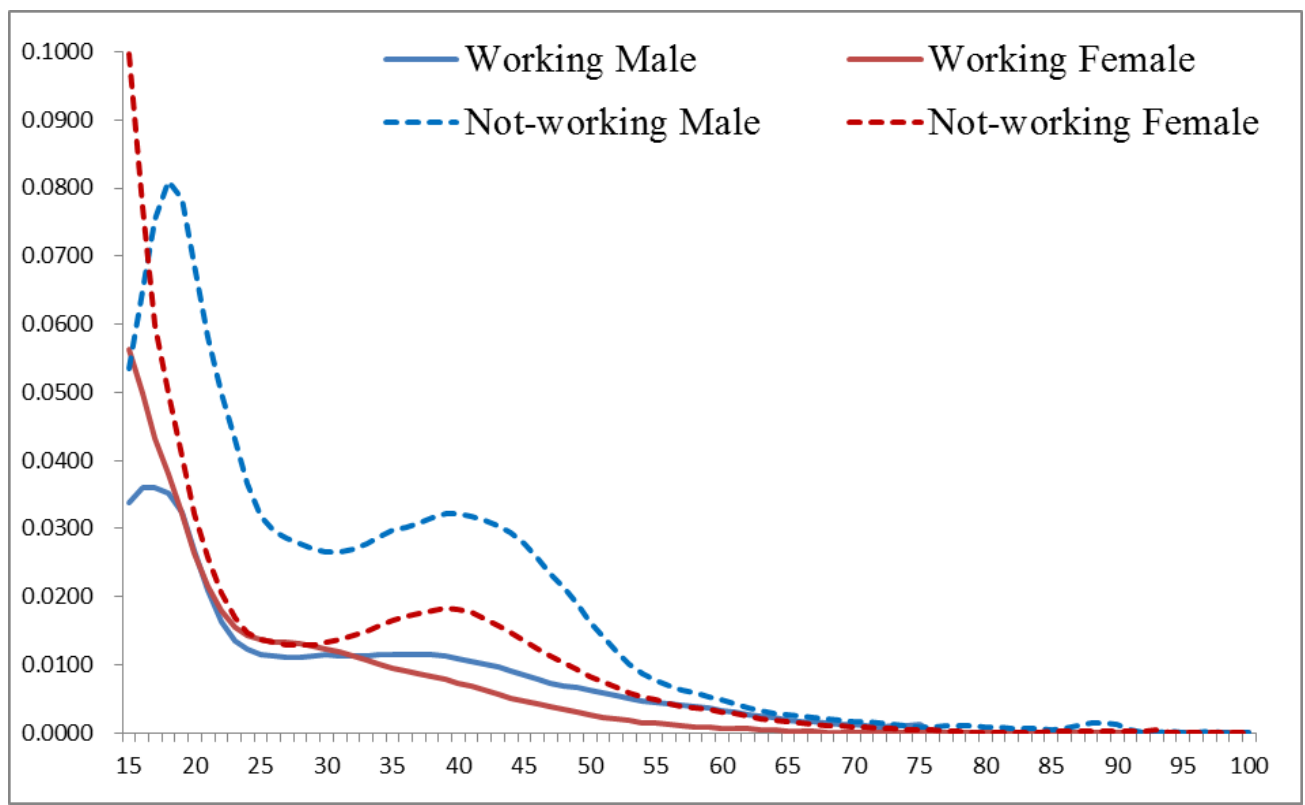

Figure 3. Transition Probabilities: The Married State to the Divorced State

The transition probabilities from the widowed state to the married state are higher for the people with jobs than for the people without jobs for both men and women (Figure 4). It may imply that having a job is one of important conditions favorable for remarriage in several aspects such as income security for the new family life and social prestige for not only men but also women. These transition probabilities rapidly decline after reaching a peak in their 20s, showing the increase of 'age effect' offsetting the employment effect on marriage at older ages. Such an age effect appears to be stronger for women than their counterpart sex of men. Although the transition probabilities from the widowed state to the married state are rather low for the people without jobs, there is a mound in their 20s for both men and women due mainly to the age effect.



Figure 4. Transition Probabilities from the Widowed State to the Married State 
The transition probabilities from the divorced state to the married state also appear to be higher for the people with jobs than the people without jobs for both men and women, implying that having a job is one of important conditions favorable for remarriage of the divorced people. It seems to be truer for women than men in their younger ages of 20 s and early 30 s. Such transition probabilities rapidly decline after reaching a peak in their 10 s for both sexes, due mainly to the increase of age effect, offsetting the employment effect on marriage at older ages. The low hill of transition probabilities for the people without jobs may be due to the age effect; it seems to be easier for the younger people even without jobs than the older people to reenter their marriage life after his or her divorce.

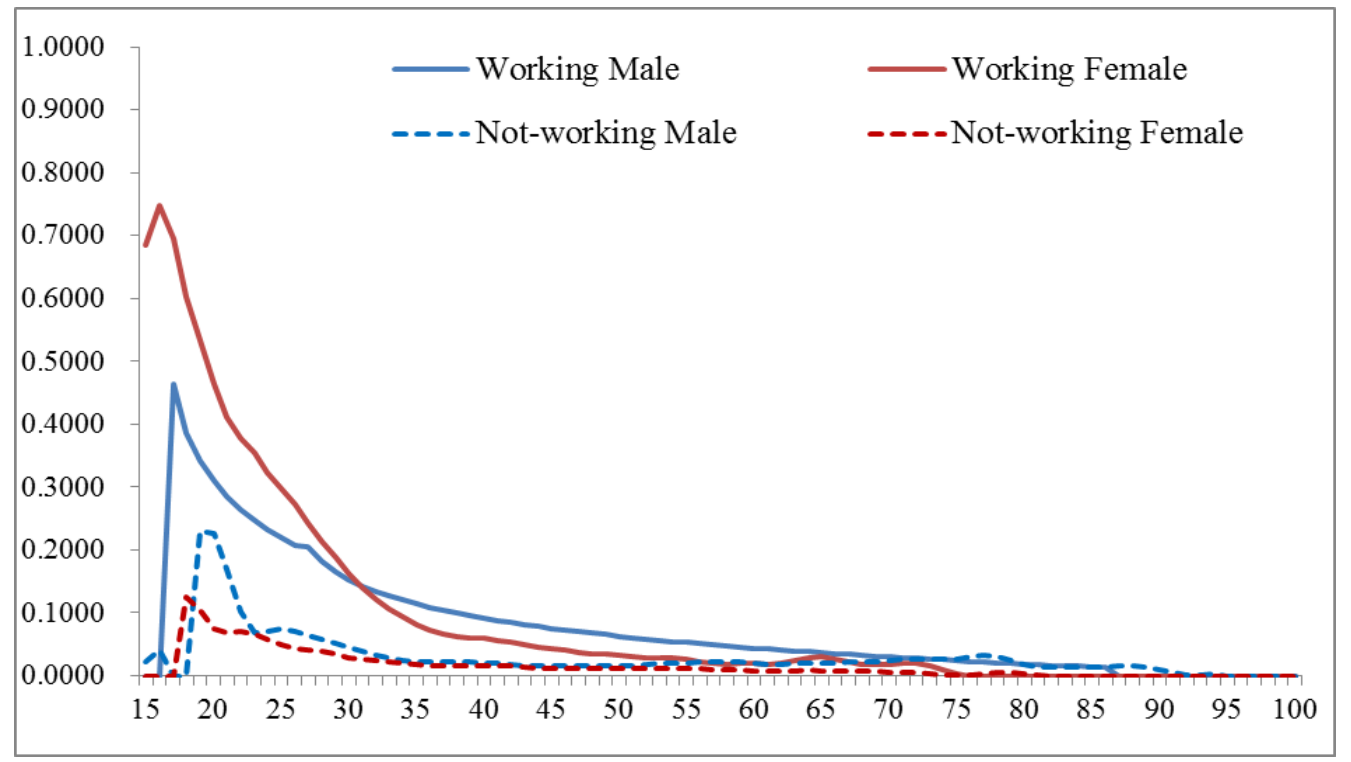

Figure 5. Transition Probabilities from the Divorced State to the Married State

\section{Conclusions}

This study made an attempt to measure the effect of employment on marriage. It may be worthwhile to note from the results that the probabilities are higher for transition from the divorced state to the married state, transition from the widowed state to the married state, transition from the single state to the married state, and transition from the married state to the divorced state, in that order, regardless of their employment status for both men and women. Having a job is more likely to expedite the transition from the single state, the widowed state, or the divorced state to the married state than having no job for both men and women. On the other hand, having no job is more likely to yield to the transition from the married state to the divorced state than having a job. Such an effect of employment status on marriage behaviors appear to be rather strong at younger ages, specifically in 20 s or 30 s, but decreases with age; the age is, in nature, a very important determinant to transit between the marital states offsetting the employment effect in older ages. The employment effect seems to be similar between two sexes, although there are some irregularities at very young ages such as 10 s or early 20 s, due mainly to a small denominator. Such a result implies that not only men but also women are dependent on their employment status to transit from one state to another when the transition probabilities by age are taken into considerations. This result is more or less different from some of previous studies which revealed mostly the existence of employment effect on marriage behaviors only for men. Thus, the findings from this 
study may strongly suggest that both job opportunities and job security should be strengthened for not only men but also women, specifically at young ages including 20 s and early 30 s, to stimulate family formation and to prevent family dissolution.

\title{
Acknowledgements
}

This work was supported by the ICT R\&D program of MSIP/IITP. [10047117, Development of Distributed/Parallel Multi-Dimensional Demographic Micro Simulation Technologies for Population Dynamics and Socio-Economic Experimentation].

\section{References}

[1] T. H. Ahn, Employment Status of Men and the Family Formation, vol. 10, no. 3, (2010), pp. 35-64.

[2] T. N. E. Greville, "Moving-weighting-average smoothing extended to the extremities of the data", Scandinavian Actuarial Journal, (1981), pp. 39-55.

[3] J. S. Kim, "Marriage Intention Among Never-Married Men and Women in Korea", Korea Journal of Population Studies, vol. 29, no. 11, (2006), pp. 57-70.

[4] S. J. Lee, "Determinants of Marriage Selection - Focused on the gender differences", Quarterly Journal of Labor Policy, vol. 5, no. 1, (2005), pp. 131-156.

[5] S. S. Lee, "Low Fertility and Policy Response in Korea", The Japanese Journal of Population, vol. 7, no. 1, (2009) March.

[6] S. S. Lee and J. H. Lee, "Cause of Continued Lowest Low Fertility and Future Policy Directions", KIHASA, (2014).

[7] S. S. Lee and H. J. Choi, "Measurement of Effect of Employment on Transition of Marital State: Using Transition Matrix of a Markov Chain", Advanced Science and Technology Letters, IRTT, vol. 96, (2015), pp. 90-94.

[8] H. M. Lim and J. B. Kim, "The Effects of Employment Status on Desired Age at Marriage", Korea Journal of Population Studies, vol. 36, no. 3, (2013), pp. 45-67.

[9] J. S. Siegel and D. A. Swanson, "The Methods and Materials of Demography", second edition. San Diego, USA: Elsevier Academic Press, (2004).

[10] "Statistics Korea", Population Prospects, (2011), pp. 2011 2060.

[11] Yoo and Hyun, "The Effect of Economic Resources on Marriage-Delaying", Korea Journal of Population Studies, vol. 33, no. 1, (2010), pp. 75-101.

[12] J. Y. Yoon, "Labor Market Integration and Transition to Marriage", Korea Journal of Population Studies, vol. 35, no. 2, (2012), pp. 159-184.

\begin{abstract}
Authors
Samsik Lee, a demographer, is a senior research fellow of Population Policy Research Division in Korea Institute for Health and Social Affairs. Lee has been involved in carrying out numerous studies on population phenomena, specifically low fertility and population aging in Korea.
\end{abstract}

Hyojin Choi, is a senior researcher of Population Policy Research Division in Korea Institute for Health and Social Affairs. 
International Journal of $u-$ and e- Service, Science and Technology Vol.8, No. 9 (2015) 